\section{ORTHODONTICS; ORAL AND MAXILLOFACIAL SURGERY}

\section{Elective orthognathic treatment} decision making: a survey of patient reasons and experiences

Stirling J, Latchford G et al. J Orthod 2007; 34: 113-127

Some patients do not appear to be making informed choices about orthognathic surgery (OGS)

Little is known about how patients make decisions regarding OGS. In this study, 138 patients who had made such decisions 18-42 months previously, or were about to make them, were asked to answer a questionnaire and be interviewed, and 31 and 30 in the respective categories agreed. The 42\% who agreed were significantly older than those who declined (mean 25 yrs v. 19yrs).

Patients had ratings for anxiety, self-esteem and body satisfaction similar to those for the general population. Consultants treating the patients rated patients' appearance overall less satisfactory than the patients themselves. Facial appearance was the main motive in seeking treatment given by patients at interview, but in questionnaires, perceived problems with occlusion and dental appearance were predominant. Two-thirds of patients weighed the benefits against the risks in order to make a decision. The authors consider that OGT patients need more support to make informed decisions.

DOI: $10.1038 /$ bdj.2007.1113

\section{ORAL PATHOLOGY}

Ameloblastic carcinoma: an analysis of 14 cases

Hall JM, Weathers DR et al. Oral Surg 2007; 103: 799-807

This very rare tumour appears to be treated best with aggressive surgery. This study is another which suggests that the current UK law on tissue removed from patients is extremely unsatisfactory.

From 1902 to 2005, 193 cases of ameloblastoma had documented treatment with retained histological material at a US hospital, and were examined by 3 pathologists who agreed that 14 had features of malignancy. Patients were aged 7 to 75 at diagnosis and 5 had signs and symptoms well before diagnosis.

Recurrence was more frequent in cases diagnosed before 1950, and treatment involved surgery, curettage, electrocautery and irradiation. Recurrence was common and frequent, and 4 out of 6 patients died with the tumour. After 1950, surgery was almost the only treatment, recurrence was less frequent, and only 1 patient died with the tumour after requesting no treatment for the $3 r d$ recurrence.

\section{ORAL MEDICINE}

\section{Oral lesions in HIV-positive dental patients - one more argument for tobacco smoking cessation}

\author{
Sroussi HY, Villines D et al. Oral Diseases 2007; 13: 324-328
}

Tobacco smoking appeared to be more related to lesions arising from immunosuppression in these patients than did HIV.

There are marked reductions in some oral lesions in HIV patients on highly-active antiretroviral treatment (HAART), but paradoxical increases in other lesions in some studies. This study reviewed the condition of 415 consecutive patients in a dedicated HIV dental clinic in Chicago.

Oral manifestations of HIV were apparent in 55\% of subjects, and 56\% smoked. Oral candidiasis was present in $39 \%$ of subjects, and $44 \%$ of smokers. Hairy leucoplakia occurred in $12 \%$ of smokers and 3\% of non-smokers. Overall, taking CD4 counts into consideration, significant inverse partial correlations for no oral lesions were identified for smoking and cigarettes per day, but for ethnicity, gender and HAART, the correlations were not significant. The authors consider smoking to be a major risk factor for oral lesions in HIV patients.

\section{DOI: $10.1038 /$ bdj.2007.1114}

\section{ENDODONTICS}

\section{Endodontic treatment outcome: effect of the permanent restoration}

Chugal NM, Clive JM et al. Oral Surg 2007; 104: 576-582

The initial periapical diagnosis appears to affect endodontic outcome more than the presence of a subsequent permanent restoration.

Coronal leakage is considered a re-infection risk in endodontics. However, there is little evidence on the effect of early permanent restoration of endodontically treated teeth. In this study, data were obtained initially for 441 root canals in 200 teeth in 120 patients.

At follow-up $4 \pm 0.5$ yrs later, permanently restored teeth/ roots $(\mathrm{n}=375)$ had a success rate of $80 \%$, compared with $60 \%$ of teeth/roots (30) with temporary restorations. However, teeth with normal preoperative periapical condition were significantly more likely to be restored with a cast restoration than teeth without. When initial periapical status was controlled in the analysis, there was no significant association between endodontic success and the presence of a permanent restoration.

DOI: 10.1038/bdj.2007.1116 